Johnson \& Wales University

ScholarsArchive@JWU

Health \& Wellness Department Faculty

Publications and Research

2017

Vulnerability to alcohol-related problems: a policy brief with implications for the regulation of alcohol marketing

Thomas F. Babor

Katherine Robaina

Jonathan K. Noel

E. Bruce Ritson

Follow this and additional works at: https://scholarsarchive.jwu.edu/health_fac

Part of the Medicine and Health Sciences Commons 


\title{
Vulnerability to alcohol-related problems: a policy brief with implications for the regulation of alcohol marketing
}

\author{
Thomas F. Babor, Katherine Robaina, Jonathan K. Noel \& E. Bruce Ritson \\ Department of Community Medicine and Health Care, University of Connecticut School of Medicine, Farmington, CT 06030, USA
}

\section{ABSTRACT}

Background and Aims The concern that alcohol advertising can have detrimental effects on vulnerable viewers has prompted the development of codes of responsible advertising practices. This paper evaluates critically the concept of vulnerability as it applies to (1) susceptibility to alcohol-related harm and (2) susceptibility to the effects of marketing, and describes its implications for the regulation of alcohol marketing. Method We describe the findings of key published studies, review papers and expert reports to determine whether these two types of vulnerability apply to population groups defined by (1) age and developmental history; (2) personality characteristics; (3) family history of alcoholism; (4) female sex and pregnancy risk; and (5) history of alcohol dependence and recovery status. Results Developmental theory and research suggest that groups defined by younger age, incomplete neurocognitive development and a history of alcohol dependence may be particularly vulnerable because of the disproportionate harm they experience from alcohol and their increased susceptibility to alcohol marketing. Children may be more susceptible to media imagery because they do not have the ability to compensate for biases in advertising portrayals and glamorized media imagery. Conclusion Young people and people with a history of alcohol dependence appear to be especially vulnerable to alcohol marketing, warranting the development of new content and exposure guidelines focused on protecting those groups to improve current self-regulation codes promoted by the alcohol industry. If adequate protections cannot be implemented through this mechanism, statutory regulations should be considered.

Keywords Adolescents, advertising, alcohol, children, cue-reactivity, marketing, regulation, sex and gender, vulnerability.

Correspondence to: Thomas F. Babor, Department of Community Medicine and Health Care, UConn School of Medicine, 263 Farmington Avenue, MC 6325, Farmington, CT 06030-6325, USA. E-mail: babor@uchc.edu

\section{INTRODUCTION}

From a public health perspective, vulnerability denotes susceptibility to poor health or illness, which can be manifested through physical, mental and social health outcomes. Although definitions of vulnerability vary $[1,2]$, for the purposes of this review, two forms of vulnerability are considered: (1) susceptibility to alcohol-related harm and (2) susceptibility to the effects of marketing.

Age and pregnancy status are recognized in the responsible marketing codes adopted by the alcohol and marketing industries as vulnerability characteristics. Some self-regulated alcohol marketing codes, for example, prohibit the use of actors who are or appear to be under the legal purchase age, presumably to protect youth from exposure to role models of the same age. Similarly, some codes prohibit the depiction of pregnant women.

Increased vulnerability to the harmful effects of alcohol and alcohol marketing may also be defined by a variety of personal attributes and individual difference factors, such as a family history of alcohol dependence, certain personality characteristics and disorders as well as psychiatric syndromes such as alcohol dependence, which may make former drinkers more likely to experience alcohol craving in response to alcohol marketing.

In addition to being vulnerable to the effects of alcohol, some populations (e.g. children) may be especially vulnerable to the effects of alcohol marketing (e.g. [3]). For example, young children may be more susceptible to media imagery because they do not have the ability to compensate for biases in advertising portrayals and glamorized media imagery. For this reason, child advocates [4] and business ethicists [1] question the ethics of marketing practices targeted to children because it is considered unfair to take advantage of groups who cannot defend themselves.

The purpose of this paper is to evaluate critically the concept of vulnerability as it applies to the marketing of alcohol products to populations defined by five types of 
personal and social characteristics: (1) age and developmental history; (2) personality characteristics; (3) family history of alcoholism; (4) female sex and pregnancy risk; and (5) drinking history and alcohol dependence.

\section{AGE AND DEVELOPMENTAL HISTORY}

Children and adolescents satisfy both criteria for a vulnerable population. Evidence shows that the architecture of the brain changes significantly and predictably during adolescence. During childhood, the volume of gray matter in the cortex increases and then declines, with the maximum gray matter volume occurring during early adolescence [5]. The decline in the volume of grey matter is accompanied by a flourish of axonal growth and refinement of cortical connections. Superfluous neurons are pruned and the structure of the adult brain gradually takes shape. This winnowing of neurons is influenced by, among other factors, the adolescent's interactions with and experiences in the outside world.

Behavioral controls, judgement and the capacity to postpone gratification do not develop fully until the grey matter of the prefrontal cortex and its connections are well established, which is completed in the mid-20s [6]. This process contrasts with the development of the limbic system, which occurs at a much earlier age. It has been hypothesized that risky impulsive behaviors result from the dissociation in development between the limbic system and the prefrontal cortex, rendering adolescents particularly prone to risky behavior such as binge drinking [7]. This may explain why alcohol-related risky behavior resulting in injury, accidents, crime and harm to others is common at this age.

Brain structures subserving socio-emotional processing are very prominent at this time, and may constitute targets for advertising, especially on social media, that emphasize bonding with friends and identification with a particular product. In late adolescence the adolescent boy or girl becomes acutely self-aware, and the judgement of peers and 'fitting in' are paramount. Because of this, alcohol may fit into the social awareness paradigm, which confers adaptive benefits as well as hazards [8].

Cross-sectional studies have shown that there are significant differences in the brain structure and function of adolescents who drink heavily and those who do not [9]. Although the dilemma of cause and effect has yet to be clarified fully, overall, heavy drinking during adolescence has been associated with lower cognitive ability and abnormal brain development. Alcohol also appears to affect the ability of young people to control their emotions and behaviors, which could lead to long-term academic, occupational and social functioning problems. Early onset of very heavy drinking is thought to increase the likelihood of developing alcohol disorders later in life, due potentially to lasting effects on brain function [7]. Although more research is needed in this area, the existing evidence is sufficient to raise serious concern [10].

Developmental theory and research suggest strongly that young children may be more susceptible to media imagery because they do not have the ability to compensate for biases in advertising portrayals and glamorized media imagery (e.g. [3]). This view is supported by research showing that prior to the age of 8 years most children do not possess the necessary cognitive skills to differentiate commercial advertising from other sources of information $[11,12]$. Even older children and adolescents who understand the purpose of advertising may not act regularly on that knowledge because they lack the ability to weigh long-term health consequences of alcohol consumption against short-term rewards [13].

Specific to alcohol, a study examining adolescents' age perceptions of characters in several beer commercials [14] found that $40 \%$ of respondents perceived at least one underage person in the advertisements; $19 \%$ of the rated commercials contained characters perceived to be underage users or intended users of alcohol, and younger adolescents were more inclined to perceive underage characters as users of the product. In a reciprocal relationship, young people who have initiated alcohol use earlier than their peers may be more vulnerable to the effects of alcohol marketing. One study found that underage drinkers tend to be more adept than same-age non-drinkers at recognizing and identifying alcohol product brand imagery in television advertisements [15], and a separate study determined that young adults (aged 18-21 years) who drink heavily perceive heavier drinking by characters portrayed in alcohol advertisements and are less likely to label this drinking as excessive [16].

\section{PERSONALITY CHARACTERISTICS AND OTHER INDIVIDUAL DIFFERENCE FACTORS}

Personality disorders (e.g. attention deficit hyperactivity disorder and conduct disorder) and personality traits such as sensation-seeking and impulsiveness have been linked to early onset of drinking and progression to alcohol dependence [17]. There is also evidence of an association between high reward sensitivity and hazardous drinking $[18,19]$. Several of these personality characteristics, particularly sensation-seeking, have been implicated in a variety of other problem behaviors, such as illicit drug use, risky driving, driving while intoxicated and high-risk sexual activity.

Such individuals may be particularly susceptible to role models who exhibit deviant behaviors, portrayed sometimes in alcohol advertisements as well as movies that contain alcohol product placements. Despite the consistent 
association of these characteristics with early onset of drinking and with later alcohol abuse (e.g. [20]), it is not possible at this time to specify the nature of the vulnerability with sufficient diagnostic accuracy to include it as a target of marketing controls.

\section{FAMILY HISTORY OF ALCOHOL DEPENDENCE}

Adult children of alcoholics meet one of the proposed criteria of a vulnerable population. They are uniquely susceptible to alcohol use. Parental problem drinking is a significant health risk to children and adolescents [21]. Children of parents who drink excessively are more likely to have substance use disorders, engage in criminal behavior and have severe psychiatric disorders, including suicidal ideation, depression and psychological disturbances. In addition to genetics, parental modeling has been identified as a primary mechanism that increases the risk of early-onset adolescent drinking in children whose parents display heavy alcohol consumption patterns [22]. In a longitudinal study that followed children from 1st to 8th grade, parental alcohol use was a significant risk factor for a female child's intention to drink [23].

A longitudinal study on the intergenerational transmission of alcoholism found that the effect of higher levels of maternal drinking and current paternal alcohol use disorders on childhood onset of drinking was mediated by disclosure of negative alcohol experiences [24]. That is, greater disclosures were associated with earlier alcohol initiation among children. Moreover, positive and negative alcohol expectancies in children are influenced by parental alcohol expectancies, with adoption of expectancies apparent by age 12 [25].

There is insufficient evidence to suggest that adult children of alcoholics either are or are not vulnerable to alcohol marketing. One study found no differences in perceptions between participants who did and who did not have a family history of alcohol problems [16]. No other studies were located on this topic.

\section{WOMEN AT RISK FOR AN ALCOHOL-EXPOSED PREGNANCY}

A woman is at risk for an alcohol-exposed pregnancy (AEP) if, in the last month, she (1) drank alcohol; (2) had vaginal intercourse with a male; and (3) did not use contraception [26]. Current research is insufficient to determine if these women should be considered a vulnerable population. There are two primary health concerns regarding alcohol use in this population. First, harm to the woman must be taken into consideration. Women typically have increased vulnerability to alcohol-related harm because of lower body weight, smaller liver capacity to metabolize alcohol and a higher proportion of body fat [27]. A recent meta-analysis that included 23 prospective studies of nearly 500000 participants concluded that moderate and heavy drinking women may have an increased risk of mortality compared to moderate and heavy drinking men [28], while the risk of liver cirrhosis was higher among women compared to men with the same level of alcohol consumption in a separate meta-analysis [29]. Alcohol use is also a risk factor for breast cancer, with some studies showing risk beginning at one to two drinks per day [30-32].

Secondly, alcohol consumption during pregnancy must be considered. Women who drink while pregnant risk giving birth to a child with physical, learning and behavioral problems, including fetal alcohol spectrum disorder (FASD) [33-39]. Alcohol can disrupt fetal development at any stage of pregnancy, including the early stages before a woman may know she is pregnant. Studies confining exposure to early gestation have concluded that facial malformations representative of FASD result from ethanol exposure during the embryonic period, specifically the first 3-8 weeks of gestation [40]. Other studies have documented decreased height (length) and weight that persist into young adulthood [41], increased rates of spontaneous abortion [42], increased craniofacial abnormalities $[43,44]$, psychiatric disorders as young adults [34] and neurobehavioral deficits [45-49]. Although studies focusing on low to moderate alcohol consumption during pregnancy have shown inconsistent results [50], the public health and medical community generally recommends that women abstain from drinking alcohol during pregnancy.

High rates of alcohol use during pregnancy have been reported in the United States (17.9\%), the Russian Federation (51.9\%) and Barcelona, Spain (45\%), with binge drinking rates of 2.7 and $20.2 \%$ reported in the United States and Russian Federation, respectively [51-53]. In the Western Cape of South Africa, $43 \%$ of women reported alcohol consumption during pregnancy [54] and rates of FAS documented in one such community are the highest in the world: $65.2-74.2$ per 1000 children in the firstgrade population [55]. An analysis of 865 meconium samples from pregnant women in Uruguay revealed that $47.3 \%$ were positive for alcohol, while only $35 \%$ disclosed drinking while pregnant [56]. These findings suggest that many pregnant women are not following medical advice not to consume alcohol during pregnancy, if they receive any advice at all.

The issue is compounded further by high rates of unintended pregnancies, during which a woman may expose her developing fetus to alcohol unintentionally before recognition of pregnancy. Using multiple data sources to estimate the incidence of all live births, abortions and miscarriages for all major geographic regions, a study by 
Sedgh, Singh \& Hussain [57] found that 85 million of the 213 million pregnancies (40\%) that occurred world-wide in 2012 were unintended. In Latin America and the Caribbean, the rate was $56 \%$. While $42 \%$ of unintended pregnancies in Latin America and the Caribbean end in induced abortion, and 39\% in North America, more than a quarter of all live births are from unintended pregnancies.

Little research has been conducted to determine if women, particularly those at risk for an AEP, are susceptible to alcohol marketing. In a study of US college students, women perceived greater alcohol consumption by the main characters in three of five alcohol advertisements viewed [16]. A study utilizing street interviews determined that men and women describe beer, wine and spirits in different ways [58]. However, the first study did not link gender with other behavior patterns and the second study did not attempt to show that different perceptions of alcohol marketing indicates susceptibility to the marketing message. Therefore, while alcohol consumption poses significant risks to a fetus and may pose increased risk to women, it is premature to consider this subset of women vulnerable in terms of alcohol marketing messages.

\section{HISTORY OF HEAVY DRINKING AND SUSCEPTIBILITY TO RELAPSE IN RECOVERING ALCOHOLICS}

Evidence supports defining alcoholics and other heavy drinkers as a vulnerable population. Long-term excessive use of alcohol has been linked to liver disease, heart disease, cancer, learning and memory problems, mental health problems and social problems [59]. The World Health Organization estimates that more than 3 million deaths per year globally are attributable to the harmful use of alcohol [60].

Some studies have shown that heavy or problem drinkers respond differently in response to alcohol cues than light or social drinkers on measures of psychophysiology [61,62], attentional bias [63,64], cognitive processing [65], urges to drink $[19,66]$ and positive affect $[63,67]$. In one experiment, 'moderate social drinkers' exposed to alcohol advertisements in magazines showed increases in skin conductance to a significantly greater extent than did 'light social drinkers' [68].

Alcohol-related images in cue-reactivity studies have been found to increase craving or urges to drink in heavy alcohol users compared to 'neutral' or control cues $[69,70,66,67,71]$. This may occur because heavy alcohol users are subject to attentional biases [72]. Individuals whose goal is to consume alcohol are easily distracted by alcohol-related stimuli and will either dismiss or pay significantly less attention to non-alcohol-related cues. The degree of attentional bias an individual exhibits is associated positively with drinking status, with heavy drinkers having significantly greater biases than non-drinkers or social drinkers, and there is evidence to suggest that attentional bias plays a causal role in triggering alcohol use in relapse and in maintaining alcohol dependence [73-75]. Moreover, craving and alcohol-related attentional bias may create a positive feedback loop whereby alcoholrelated stimuli become more salient as cravings increase and cravings increase as greater attention is paid to alcohol-related stimuli [73].

Using functional neuroimaging as a tool to understand reactivity to alcohol-related cues, a meta-analysis identified greater neural activation after exposure to alcohol-related stimuli in heavy alcohol users in the ventral striatum and ventral anterior cingulate cortex [76]. Activity in the ventral striatum was correlated positively with severity of dependence, amount of drinking, impaired control and magnitude of craving. In another study [77], teenagers with alcohol use disorders showed greater brain activation to pictures of alcoholic beverages than control youths, predominantly in areas linked to reward, desire and positive affect. The degree of brain response was highest in youths who reported greater desire to drink and who consumed alcohol more frequently.

Importantly, cue-reactivity is predictive of alcohol consumption and relapse after treatment in alcoholics [78]. For example, participants in an alcohol treatment program who exhibited increased cue-elicited alcohol craving had higher odds of relapse [79], and among alcoholics undergoing in-patient treatment $8-10 \%$ of the variance in alcohol consumption after discharge was explained by the desire to drink after cue-reactivity sessions [80].

\section{IMPLICATIONS FOR THE REGULATION OF ALCOHOL MARKETING}

What moral responsibilities do marketers of alcoholic beverages have when they consider marketing to vulnerable groups? Do both types of vulnerability need to be present for protection to be afforded, or would the first type be a sufficient criterion? These are some of the questions this essay has attempted to answer. Table 1 provides a box score summary to the evidence for two types of vulnerability in five groups of drinkers. The table indicates that both types of vulnerability are present in at least two groups.

The risks of alcohol consumption in young people are well recognized and are reflected in various forms of 'permitted age' legislation around the world, including regulations and industry self-regulations on exposure of children and adolescents to alcohol marketing. It is now clear that these prohibitions are based soundly on a demonstrable biological vulnerability that shows that the brain is not biologically mature until early adult life.

Many cultures have established laws about the age at which young people are permitted to drink or be served 
Table 1 Evidence for two types of vulnerability in five groups of drinkers.

Susceptibility to alcohol-related harm Susceptibility to the effects of marketing

\begin{tabular}{lll}
\hline Children and adolescents & $\mathrm{x}$ & $\mathrm{x}$ \\
Individuals with sensation-seeking and impulsiveness traits & $\mathrm{x}$ & $?$ \\
Adult children of alcoholics & $\mathrm{x}$ & \\
Women at risk for an alcohol exposed pregnancy & $\mathrm{x}$ & $\mathrm{x}$ \\
Alcoholics and other heavy drinkers & $\mathrm{x}$ & \\
\hline
\end{tabular}

alcohol. This shows that society has been aware of the dangers attendant on adolescent drinking both to the drinker and to public order. Vulnerability is well recognized, but the biological underpinning of this conventional wisdom adds another dimension to our appreciation of the risks and shows that the brain itself matures later than has been commonly thought. The brain evolves throughout adolescence and into early adult life. The impulsiveness and risk-taking evident in many adolescents, coupled with the relatively late development of critical faculties, has a neurochemical substrate. The architecture and activity of the brain are very malleable over these years, and alcohol can impair successful maturation. This makes the young person uniquely vulnerable to the blandishments of marketing in all its forms. An additional reason for restraint is that the psychoactive effects of alcohol on the immature brain are particularly potent, with damaging consequences to self and others.

Social learning theory [81] provides insights into the link between advertising, purchase behavior, onset of drinking and heavy drinking. In addition to social modeling of drinking behavior and the frequent association of social reinforcement with drinking, learned alcohol expectancies are another factor thought to mediate the relationship between vulnerability factors, alcohol marketing and alcohol-related problems. These expectations have been found to affect the early onset of drinking, behavior during intoxication and the development of alcohol abuse [82]. Other evidence indicates that marketing can affect young people's alcohol expectancies in a way that facilitates positive and negative affect regulation [83].

Beyond groups defined by age and developmental history, one other group — alcoholics — may be particularly vulnerable because of the disproportionate harm they experience from alcohol and their increased susceptibility to alcohol marketing. This group meets the two proposed criteria that define vulnerability for marketing purposes, thereby warranting an expanded definition of vulnerability as it applies to alcohol marketing.

More research is needed to expand the definition to women at risk of an AEP, adult children of alcoholics or other populations based on psychological characteristics. For example, extensive research demonstrates the dangers of alcohol consumption during pregnancy, which was reiterated in a 1981 US Surgeon General's advisory urging women who are pregnant or who might become pregnant to abstain from alcohol use, and by the US Secretary of Health and Human Services [84], the Centers for Disease Control and the Substance Abuse and Mental Health Services Administration (SAMHSA) [51]. However, there is insufficient evidence to suggest that women who may become pregnant are uniquely susceptible to alcohol marketing, even though non-pregnant women of childbearing age may benefit from the same protections provided to pregnant women regarding alcohol advertising.

Additional research should include observational and experimental studies. Similar to existing studies on the effects of alcohol marketing exposure, longitudinal cohort studies of youth and adults that are designed specifically to identify vulnerable and potentially vulnerable populations can determine if changes in alcohol consumption and alcohol-related consequences due to marketing exposures are greater in these populations. New experimental research can parallel the cue-exposure research performed on populations of alcoholics and heavy alcohol users. For example, trials can be implemented to determine if vulnerable or potentially vulnerable populations have greater alcohol cravings after exposure to alcohol marketing and if these populations show attentional bias towards such materials.

The populations discussed in this paper are not insignificant. World-wide, $16.0 \%$ of the $15+$ population were heavy episodic drinkers in 2010 [60]. Historically, one in eight Americans were children of alcoholics [85], and recent evidence suggests that $20 \%$ of the Swedish populations have parents with alcohol problems [86]. Moreover, approximately 2 million women in the United States are at risk for an alcohol-exposed pregnancy [26].

In conclusion, this review suggests that new content and exposure guidelines should be drafted to improve current self-regulation codes by expanding them to vulnerable groups of adults. To the extent that both theory and empirical research suggest that populations defined by age and developmental history may be particularly susceptible to alcohol marketing, there are ample grounds for strengthening the protections used in many countries that limit exposure to potentially harmful marketing content, especially in light of evidence showing that industry self-regulation measures 
are ineffective in protecting age vulnerable groups from exposure to potentially harmful content [87]. If adequate protections cannot be implemented through this mechanism, then statutory regulation should be considered.

\section{Declaration of interests}

None.

\section{Acknowledgements}

This is one of a series of papers published in a Supplement to Addiction entitled: 'The Regulation of Alcohol Marketing: From Research to Public Health Policy'. Funding for the publication of the Supplement was provided by Alcohol Research UK and the Institute of Alcohol Studies. Preliminary versions of the majority of these manuscripts were first presented at a meeting organized by the Pan American Health Organization.

\section{References}

1. Brenkert G. Marketing and the vulnerable. Business Ethics $Q$ 1998; 1: 7-20.

2. Shi L., Stevens G. D., editors. Vulnerable Populations in the United States, 2nd edn. Hoboken, NJ: John Wiley \& Sons; 2011.

3. Brucks M., Armstrong G. M., Goldberg M. E. Children's use of cognitive defenses against television advertising: a cognitive response approach. J Consum Res 1988; 14: 471-82.

4. Harris J. L., Pomeranz J. L., Lobstein T., Brownell K. D. A crisis in the marketplace: how food marketing contributes to childhood obesity and what can be done. Annu Rev Public Health 2009; 30: 211-25.

5. Peeters M., Vollebergh W. A., Wiers R. W., Field M. Psychological changes and cognitive impairments in adolescent heavy drinkers. Alcohol Alcohol 2014; 49: 182-6.

6. National Institute for Mental Health. The-teen-brainstill-under-construction. NIH 2011 NIH Publication no. 11-4929. 2011. Available at: www.nimh.nih.gov/health/.../ the-teen-brain-still-under-construction/ (accessed 23 May 2016) (Archived at http://www.webcitation.org/6lsHazjyD on 8 November 2016).

7. Bava S., Tapert S. F. Adolescent brain development and the risk for alcohol and other drug problems. Neuropsychol Rev Neurosci 2010; 20: 398-413.

8. Crone E. A., Dahl E. D. Understanding adolescence as a period of social-affective engagement and goal flexibility. Nat Rev 2012; 13: 636-50.

9. Welch K. A., Carson A., Lawrie S. M. Brain structure in adolescents and young adults with alcohol problems: systematic review of imaging studies. Alcohol Alcohol 2013; 48: 433-44.

10. Squeglia L. M., Tapert S. F., Sullivan E. V., Jacobus J., Meloy M. J., T. R. et al. Brain development in heavy drinking adolescents. Am J Psychiatry 2015; 172: 531-42.

11. Institute of Medicine. Food marketing to children and youth: threat or opportunity? Washington, DC: The National Academies Press; 2004. Available at: https://www.nap.edu/ catalog/11514/food-marketing-to-children-and-youth-threator-opportunity (accessed 20 May 2016) (Archived at http:// www.webcitation.org/6lsIfsclo on 8 November 2016).
12. Harris J. L., Graff S. K. Protecting children from harmful food marketing: options for local government to make a difference. Prev Chronic Dis 2011; 8: A92.

13. Pechmann C., Levine L., Loughlin S., Leslie F. Impulsive and self-conscious: adolescents' vulnerability to advertising and promotion. J Public Policy Market 2005; 24: 202-21.

14. Slater M. D., Rouner D., Murphy K., Beauvais F., Van Leuven J., Rodríguez M. D. Male adolescents' reactions to TV beer advertisements: the effects of sports content and programming context. J Stud Alcohol 1996; 57: 425-33.

15. Aitken P. P., Leathar D. S., Scott A. C. Ten- to sixteen-year-olds' perceptions of advertisements for alcoholic drinks. Alcohol Alcohol 1988; 23: 491-500.

16. Proctor D. C., Babor T. F., Xuan Z. Effects of cautionary messages and vulnerability factors on viewers' perceptions of alcohol advertisements. J Stud Alcohol 2005; 66: 648-57.

17. Sher K. J., Grekin E. R., Williams N. A. The development of alcohol use disorders. Апnи Rev Clin Psychol 2005; 1: 493-523.

18. Dawe S., Loxton N. J. The role of impulsivity in the development of substance use and eating disorders. Neurosci Biobehav Rev 2004; 28: 343-51.

19. Kambouropoulos N., Staiger P. K. The influence of sensitivity to reward on reactivity to alcohol-related cues. Addiction 2001; 96: 1175-85.

20. Colder C. R., O'Connor R. Attention bias and disinhibited behavior as predictors of alcohol use and enhancement reasons for drinking. Psychol Addict Behav 2002; 16: 325.

21. Plant M. A., Orford J., Grant M. The effects on children and adolescents of parents' excessive drinking: an international review. Public Health Rep 1989; 104: 433-42.

22. Ryan S. M., Jorm A. F., Lubman D. I. Parenting factors associated with reduced adolescent alcohol use: a systematic review of longitudinal studies. Aust NZ J Psychiatry 2010; 44: 774-83.

23. Tildesley E. A., Andrews J. A. The development of children's intentions to use alcohol: direct and indirect effects of parent alcohol use and parenting behaviors. Psychol Addict Behav 2008; 22: 326-39.

24. Handley E. D., Chassin L. Alcohol-specific parenting as a mechanism of parental drinking and alcohol use disorder risk on adolescent alcohol use onset. J Stud Alcohol Drugs 2013; 74: 684-93.

25. Donovan J. E., Molina B. S., Kelly T. M. Alcohol outcome expectancies as socially shared and socialized beliefs. Psychol Addict Behav 2009; 23: 248-59.

26. Cannon M. J., Guo J., Denny C. H., Green P. P., Miracle H., Sniezek J. E. et al. Prevalence and characteristics of women at risk for an alcohol-exposed pregnancy (AEP) in the United States: estimates from the National Survey of Family Growth. Matern Child Health J 2015; 19: 776-82.

27. World Health Organization. Global Status Report on Alcohol. Geneva: World Health Organization; 2014.

28. Zheng Y. L., Lian F., Shi Q., Zhang C., Chen Y. W., Zhou Y. H. et al. Alcohol intake and associated risk of major cardiovascular outcomes in women compared with men: a systematic review and meta-analysis of prospective observational studies. BMC Public Health 2015; 15: 773.

29. Rehm J., Taylor B., Mohapatra S., Irving H., Baliunas D., Patra J. et al. Alcohol as a risk factor for liver cirrhosis: a systematic review and meta-analysis. Drug Alcohol Rev 2010; 29: 437-45. 
30. Singletary K. W., Gapstur S. M. Alcohol and breast cancer: review of epidemiologic and experimental evidence and potential mechanisms. JAMA 2001; 286: 2143-51.

31. Scoccianti C., Lauby-Secretan B., Bello P. Y., Chajes V., Romieu I. Female breast cancer and alcohol consumption: a review of the literature. Am J Prev Med 2014; 46: S16-25.

32. Qian F., Ogundiran T., Hou N., Ndom P., Gakwaya A., Jombwe J. et al. Alcohol consumption and breast cancer risk among women in three sub-Saharan African countries. PLOS ONE 2014; 9: e106908.

33. Barr H. M., Streissguth A. P. Identifying maternal selfreported alcohol use associated with fetal alcohol spectrum disorders. Alcohol Clin Exp Res 2001; 25: 283-7.

34. Barr H. M., Bookstein F. L., O'Malley K. D., Connor P. D., Huggins J. E., Streissguth A. P. Binge drinking during pregnancy as a predictor of psychiatric disorders on the structured clinical interview for DSM-IV in young adult offspring. Am J Psychiatry 2006; 163: 1061-5.

35. Henderson J., Kesmodel U., Gray R. Systematic review of the fetal effects of prenatal binge-drinking. J Epidemiol Community Health 2007; 61: 1069-73.

36. Lewis S. J., Zuccolo L., Smith G. D., Macleod J., Rodriguez S., Draper E. S. et al. Fetal alcohol exposure and IQ at age 8: evidence from a population-based birth-cohort study. PLOS ONE 2012; 7: e49407.

37. Murray J., Burgess S., Zuccolo L., Hickman M., Gray R., Lewis S. J. Moderate alcohol drinking in pregnancy increases risk for children's persistent conduct problems: causal effects in a Mendelian randomisation study. J Child Psychol Psychiatry 2016; 57: 575-84.

38. Sokol R. J., Delaney-Black V., Nordstrom B. Fetal alcohol spectrum disorder. JAMA 2003; 290: 2296-9.

39. Zuccolo L., Lewis S. J., Smith G. D., Sayal K., Draper E. S., Fraser R. et al. Prenatal alcohol exposure and offspring cognition and school performance. A 'Mendelian randomization' natural experiment. Int J Epidemiol 2013; 42: 1358-70.

40. Coles C. Critical periods for prenatal alcohol exposure: evidence from animal and human studies. Alcohol Res Health 1994; 18: 22.

41. Carter R. C., Jacobson J. L., Sokol R. J., Avison M. J., Jacobson S. W. Fetal alcohol-related growth restriction from birth through young adulthood and moderating effects of maternal prepregnancy weight. Alcohol Clin Exp Res 2013; 37: 452-62.

42. Andersen A. M., Andersen P. K., Olsen J., Grønbæk M., Strandberg-Larsen K. Moderate alcohol intake during pregnancy and risk of fetal death. Int J Epidemiol 2012; 41: 405-13.

43. Sulik K. K., Cook C. S., Webster W. S. Teratogens and craniofacial malformations: relationships to cell death. Development 1988; 103: 213-32.

44. Sulik K. K. Genesis of alcohol-induced craniofacial dysmorphism. Exp Biol Med 2005; 230: 366-75.

45. Jacobson J. L., Jacobson S. W., Sokol R. J., Martier S. S., Ager J. W., Kaplan-Estrin M. G. Teratogenic effects of alcohol on infant development. Alcohol Clin Exp Res 1993; 17: 174-83.

46. Jacobson S. W., Jacobson J. L., Sokol R. J. Effects of fetal alcohol exposure on infant reaction time. Alcohol Clin Exp Res 1994; 18: $1125-32$.

47. Burden M. J., Jacobson S. W., Jacobson J. L. Relation of prenatal alcohol exposure to cognitive processing speed and efficiency in childhood. Alcohol Clin Exp Res 2005; 29: 1473-83.
48. Burden M. J., Jacobson S. W., Sokol R. J., Jacobson J. L. Effects of prenatal alcohol exposure on attention and working memory at 7.5 years of age. Alcohol Clin Exp Res 2005; 29: 443-52.

49. Riley E. P., McGee C. L. Fetal alcohol spectrum disorders: an overview with emphasis on changes in brain and behavior. Exp Biol Med 2005; 230: 357-65.

50. Henderson J., Gray R., Brocklehurst P. Systematic review of effects of low-moderate prenatal alcohol exposure on pregnancy outcome. Br J Obstet Gynaecol 2007; 114: $43-52$.

51. Substance Abuse and Mental Health Services Administration (SAMHSA). Results from the 2012 National Survey on Drug Use and Health: Summary of National Findings, NSDUH Series H-46. HHS Publication No. (SMA) 13-4795. Rockville, MD: SAMHSA; 2013.

52. Chambers C. D., Kavteladze L., Joutchenko L., Bakhireva L. N., Jones K. L. Alcohol consumption patterns among pregnant women in the Moscow region of the Russian Federation. Alcohol 2006; 38: 133-7.

53. Garcia-Algar O., Kulaga V., Gareri J., Koren G., Vall O., Zuccaro P. et al. Alarming prevalence of fetal alcohol exposure in a Mediterranean city. Ther Drug Monit 2008; 30: 249-54.

54. Croxford J., Viljoen D. Alcohol consumption by pregnant women in the Western Cape. S Afr Med J 1999; 89: 962-5.

55. Viljoen D. L., Phillip Gossage J., Brooke L., Adnams C. M., Jones K. L., Robinson L. K. et al. Fetal Alcohol syndrome epidemiology in a South African Community: a second study of a very high prevalence area. J Stud Alcohol 2005; 66: 593-604.

56. Hutson J. R., Magri R., Gareri J. N., Koren G. The incidence of prenatal alcohol exposure in Montevideo Uruguay as determined by meconium analysis. Ther Drug Monit 2010; 32: 311-17.

57. Sedgh G., Singh S., Hussain R. Intended and unintended pregnancies worldwide in 2012 and recent trends. Stud Fam Plann 2014; 45: 301-14.

58. Unwin T. Images of alcohol: perceptions and the influence of advertising. J Wine Res 1992; 3: 205-29.

59. National Institute of Alcohol Abuse and Alcoholism (NIAAA). Tenth special report to the U.S. Congress on alcohol and health. Bethesda, MD: NIAAA; 2000. Available at: http:// pubs.niaaa.nih.gov/publications/10Report/10thSpecial Report.pdf (accessed 9 May 2016) (Archived at http://www. webcitation.org/6lsIukvyy on 8 November 2016).

60. Fleischmann A., Poznyak V., Rekve D., Renström M. Global status report on alcohol and health 2014. 2014 Geneva: World Health Organization. Available at: http://www.who. int/substance_abuse/publications/global_alcohol_report/ msb_gsr_2014_1.pdf?ua=1 (accessed 23 March 2016) (Archived at http://www.webcitation.org/6lsJ1iIqp on 8 November 2016).

61. Herrmann M. J., Weijers H. G., Wiesbeck G. A., Böning J., Fallgatter A. J. Alcohol cue-reactivity in heavy and light social drinkers as revealed by event-related potentials. Alcohol Alcohol 2001; 36: 588-93.

62. Ihssen N., Cox W. M., Wigget A., Fadardi J. S., Linden D. E. J. Differentiating heavy from light drinkers by neural responses to visual alcohol cues and other motivational stimuli. Cereb Cortex 2011; 21: 1408-15.

63. Field M., Mogg K., Zetteler J., Bradley B. P. Attentional biases for alcohol cues in heavy and light social drinkers: the roles 
of initial orienting and maintained attention. Psychopharmacology (Berl) 2004; 176: 88-93.

64. Townshend J., Duka T. Attentional bias associated with alcohol cues: differences between heavy and occasional social drinkers. Psychopharmacology (Berl) 2001; 157: 67-74.

65. Cox W. M., Yeates G. N., Regan C. M. Effects of alcohol cues on cognitive processing in heavy and light drinkers. Drug Alcohol Depend 1999; 55: 85-9.

66. Pronk T., van Duersen D. S., Beraha E. M., Larsen H., Wiers R. W. Validation of the Amsterdam Beverage Picture Set: a controlled picture set for cognitive bias measurement and modification paradigms. Alcohol Clin Exp Res 2015; 39: 2047-55.

67. Pulido C., Brown S. A., Cummins K., Paulus M. P., Tapert S. F. Alcohol cue reactivity task development. Addict Behav 2010; 35: 84-90.

68. Cassisi J. E., Delehant M., Tsoutsouris J. S., Levin J. Psychophysiological reactivity to alcohol advertising in light and moderate social drinkers. Addict Behav 1998; 23: 267-74.

69. Billieux J., Khazaal Y., Oliveira S., de Timary P., Edel Y., Zebouni F. et al. The Geneva Appetitive Alcohol Pictures (GAAP): development and preliminary validation. Eur Addict Res 2011; 17: 225-30.

70. Lovett D. E., Ham L. S., Veilleux J. C. Psychometric evaluation of a standardized set of alcohol cue photographs to assess craving. Addict Behav 2015; 48: 58-61.

71. Carter B. L., Tiffany S. T. Meta-analysis of cue-reactivity in addiction research. Addiction 1999; 94: 327-40.

72. Bar-Haim Y., Lamy D., Pergamin L., Bakermans-Kranenburg M. J., van IJzendoorn M. H. Threat-related attentional bias in anxious and nonanxious individuals: a meta-analytic study. Psychol Bull 2007; 133: 1-24.

73. Field M., Cox W. M. Attentional bias in addictive behaviors: a review of its development, causes, and consequences. Drug Alcohol Depend 2008; 97: 1-20.

74. Cox W. M., Hogan L. M., Kristian M. R., Race J. H. Alcohol attentional bias as a predictor of alcohol abusers' treatment outcome. Drug Alcohol Depend 2002; 68: 237-43.

75. Cox W. M., Pothos E. M., Hosier S. G. Cognitive-motivational predictors of excessive drinkers' success in changing. Psychopharmacology (Berl) 2007; 192: 499-510.

76. Schacht J. P., Anton R. F., Myrick H. Functional neuroimaging studies of alcohol cue reactivity: a quantitative meta-analysis and systematic review. Addict Biol 2013; 18: 121-33.
77. Tapert S. F., Cheung E. H., Brown G. G., Frank L. R., Paulus M. P., Schweinsburg A. D. et al. Neural response to alcohol stimuli in adolescents with alcohol use disorder. Arch Gen Psychiatry 2003; 60: 727-35.

78. Rohsenow D. J., Monti P. M., Rubonis A. V., Sirota A. D., Niaura R. S., Colby S. M. et al. Cue reactivity as a predictor of drinking among male alcoholics. J Consult Clin Psychol 1994; 62: 620-6.

79. Papachristou H., Nederkoorn C., Giesen J. C., Jansen A. Cue reactivity during treatment, and not impulsivity, predicts an initial lapse after treatment in alcohol use disorders. Addict Behav 2014; 39: 737-9.

80. Litt M. D., Cooney N. L., Morse P. Reactivity to alcohol-related stimuli in the laboratory and in the field: predictors of craving in treated alcoholics. Addiction 2000; 95: 889-900.

81. Bandura A. Social cognitive theory of mass communications. In: Bryant J., Zillman D., editors. Media Effects: Advances in Theory and Research. Hillsdale, NJ: Lawrence Erlbaum; 2002, pp. 121-53.

82. Grube J., Wallack L. Television beer advertising and drinking knowledge, beliefs, and intentions among schoolchildren. Am J Public Health 1994; 84: 254-9.

83. Anderson P., De Bruijn A., Angus K., Gordon R., Hastings G. Impact of alcohol advertising and media exposure on adolescent alcohol use: a systematic review of longitudinal studies. Alcohol Alcohol 2009; 44: 229-43.

84. United States Department of Health and Human Services, Office of the Surgeon General. Press release: U.S. Surgeon General Releases Advisory on Alcohol Use in Pregnancy. Bethesda, MD: Department of Health and Human Services; 2005. Available at: https://wayback.archive-it.org/3926/ 20140421162517/http://www.surgeongeneral.gov/news/ 2005/02/sg02222005.html (accessed 23 March 2016).

85. Mathew R. J., Wilson W. H., Blazer D. G., George L. K. Psychiatric disorders in adult children of alcoholics: data from the Epidemiologic Catchment Area project. Am J Psychiatry 1993; 150: 793-800.

86. Elgán T. H., Leifman H. Prevalence of adolescents who perceive their parents to have alcohol problems: a Swedish national survey using a web panel. Scand J Public Health 2013; 41: 680-3.

87. Noel J. K., Babor T. F., Robaina K. Industry self-regulation of alcohol marketing: a systematic review of content and exposure research. Addiction 2017; 112(Suppl. 1): 28-50. 